\title{
Transcranial Doppler ultrasonography in neurological surgery and neurocritical care
}

\author{
Robert H. Bonow, MD, ${ }^{1}$ Christopher C. Young, MD, PhD, ${ }^{1}$ David I. Bass, MD, PhD, ${ }^{1}$ \\ Anne Moore, BSN, RVT, ${ }^{1}$ and Michael R. Levitt, MD'-4

\begin{abstract}
Departments of ${ }^{1}$ Neurological Surgery, ${ }^{2}$ Radiology, ${ }^{3}$ Mechanical Engineering, and ${ }^{4}$ Stroke and Applied Neuroscience Center, University of Washington, Seattle, Washington
\end{abstract}

\begin{abstract}
Transcranial Doppler (TCD) ultrasonography is an inexpensive, noninvasive means of measuring blood flow within the arteries of the brain. In this review, the authors outline the technology underlying TCD ultrasonography and describe its uses in patients with neurosurgical diseases. One of the most common uses of TCD ultrasonography is monitoring for vasospasm following subarachnoid hemorrhage. In this setting, elevated blood flow velocities serve as a proxy for vasospasm and can herald the onset of ischemia. TCD ultrasonography is also useful in the evaluation and management of occlusive cerebrovascular disease. Monitoring for microembolic signals enables stratification of stroke risk due to carotid stenosis and can also be used to clarify stroke etiology. TCD ultrasonography can identify patients with exhausted cerebrovascular reserve, and after extracranial-intracranial bypass procedures it can be used to assess adequacy of flow through the graft. Finally, assessment of cerebral autoregulation can be performed using TCD ultrasonography, providing data important to the management of patients with severe traumatic brain injury. As the clinical applications of TCD ultrasonography have expanded over time, so has their importance in the management of neurosurgical patients. Familiarity with this diagnostic tool is crucial for the modern neurological surgeon.
\end{abstract}

https://thejns.org/doi/abs/10.3171/2019.9.FOCUS19611

KEYWORDS transcranial Doppler ultrasonography; vasospasm; stroke; traumatic brain injury; neurocritical care

$\mathrm{T}$ RANSCRANIAL Doppler (TCD) ultrasonography is an inexpensive, noninvasive means of measuring blood flow within the arteries of the brain. First described by Aaslid and colleagues in 1982, indications for its use have expanded dramatically. ${ }^{2}$ Today, TCD ultrasonography is routinely used to guide the management of patients with a range of pathologies, including occlusive cerebrovascular disease, subarachnoid hemorrhage (SAH), and trauma. The goal of this review is to outline the technology underlying TCD ultrasonography, the techniques used to perform TCD ultrasonography examinations, and common uses for the blood flow data that can be generated with TCD studies.

\section{Technical Background}

Doppler ultrasound detects motion using the difference in frequency between emitted ultrasonic waves and the returning echoes. ${ }^{49}$ This difference is proportional to the velocity of the moving object; if an object is stationary with respect to the transceiver, there is no Doppler shift. Importantly, only the component of velocity parallel to the ultrasound beam can be measured directly; any angle between the direction of movement and the beam must be mathematically accounted for. Inaccuracies can be introduced with this correction if the angle is incorrectly estimated, with error increasing as the angle approaches $90^{\circ} .{ }^{49}$ The depth of the insonated vessel can be estimated using pulsed-wave Doppler, in which the transceiver emits distinct acoustic pulses and measures the time required for their return. Using a technique termed "range gating," modern equipment is able to selectively record signals from specific depths, allowing velocity to be recorded at distinct points along a vessel..$^{33}$

Velocities in all of the major intracranial vessels can

ABBREVIATIONS ACA = anterior cerebral artery; $\mathrm{BA}=$ basilar artery; $\mathrm{CBF}=$ cerebral blood flow; $\mathrm{CPP}=$ cerebral perfusion pressure; $\mathrm{CVR}=$ cerebral vascular resistance; $\mathrm{DCl}=$ delayed cerebral ischemia; eCVR = estimated cerebrovascular reserve; ICA = internal carotid artery; ICP = intracranial pressure; LR = Lindegaard ratio; MAP = mean arterial pressure; $\mathrm{MCA}=$ middle cerebral artery; MFV = mean flow velocity; $\mathrm{PCA}=$ posterior cerebral artery; $\mathrm{PFO}=$ patent foramen ovale; $\mathrm{SAH}=$ subarachnoid hemorrhage; $\mathrm{TCD}=$ transcranial Doppler; TEE = transesophageal echocardiography; VA = vertebral artery; VMR = vasomotor reserve.

SUBMITTED July 29, 2019. ACCEPTED September 4, 2019.

INCLUDE WHEN CITING DOI: 10.3171/2019.9.FOCUS19611. 
be measured using one of 3 "windows." Because intracranial structures are not visualized using standard TCD ultrasonography equipment, identification of the vasculature requires the use of anatomical landmarks to properly angle the transceiver. The direction of flow at prespecified sampling depths further aids in vessel identification. Table 1 lists the parameters used in our laboratory for positive identification.

TCD findings are highly dependent on the experience and skill of the operator, who must manually position the probe to obtain measurements along the axis of the vessel by detecting the position with the highest velocity. Furthermore, variations in anatomy can make identification challenging if not impossible, particularly for the vertebral artery (VA) and basilar artery (BA). In approximately $10 \%-20 \%$ of patients, insonation of the terminal internal carotid artery (ICA), middle cerebral artery (MCA), anterior cerebral artery (ACA), and posterior cerebral artery (PCA) is not possible due to hyperostosis of the temporal bone. ${ }^{34}$ Following a craniotomy, the temporal window may be impaired due to hemostatic agent or metal plates at the surgical site, or it may be enhanced due to bony defects. ${ }^{33}$

Other physiological parameters can influence cerebral blood flow (CBF) velocity, including heart rate, blood pressure, hematocrit, and $\mathrm{PaCO}_{2}$. These values should be recorded with the TCD velocities to allow for serial comparisons over time and to provide context for interpretation.

\section{Subarachnoid Hemorrhage}

A major complication of aneurysmal subarachnoid hemorrhage (SAH) is the development of vasospasm and delayed cerebral ischemia (DCI). ${ }^{12}$ Between $30 \%$ and $70 \%$ of patients develop angiographic vasospasm after aneurysmal SAH, and half of these patients may develop symptomatic DCI, $17,22,45$ with the incidence peaking in the 2 nd week after ictus. ${ }^{17,22}$ Hypertension, cigarette use, and SAH volume are associated with vasospasm and DCI, with the latter showing the strongest association..$^{21,30}$

\section{Diagnosis of Vasospasm and DCI}

Angiographic vasospasm typically precedes $\mathrm{DCI} .{ }^{45}$
Therefore, early detection of vasospasm may provide a window for intervention to prevent neurological deterioration. ${ }^{12}$ In 2012, the American Heart Association guidelines for the management of SAH recommended the use of TCD ultrasonography for monitoring of development of arterial vasospasm with class IIa/level B evidence. ${ }^{12}$

Based on Bernoulli's principle, the velocity of blood flow in an artery is inversely related to the diameter of the artery. ${ }^{2}$ During vasospasm, as the arterial diameter decreases, the velocity of blood flow increases. Therefore, changes in the velocity of blood flow can be used to estimate changes in the vessel diameter and detect vasospasm. Measured flow velocities can be compared to standard measurements and baseline values to infer changes in the vessel diameter and the presence of vasospasm. ${ }^{45}$

\section{Interpretation of TCD Parameters}

Various parameters are measured and calculated during TCD ultrasonography to provide information regarding the vessel of interest. The mean flow velocity (MFV) is calculated from the peak systolic flow velocity $\left(\mathrm{V}_{\mathrm{s}}\right)$ and end-diastolic flow velocity $\left(\mathrm{V}_{\mathrm{d}}\right)$ according to the equation $\mathrm{MFV}=\left(\mathrm{V}_{\mathrm{s}}-\mathrm{V}_{\mathrm{d}} / 3\right)+\mathrm{V}_{\mathrm{d}}$ (Fig. 1). ${ }^{45}$ In certain physiological states, intracranial velocities increase in the absence of spasm. The Lindegaard ratio (LR) normalizes the MFV of the MCA to that of the ICA to correct for this (LR = $\left.\mathrm{MFV}_{\mathrm{MCA}} / \mathrm{MFV}_{\mathrm{ICA}}\right) \cdot{ }^{39}$ In vasospasm, MFV $\mathrm{MCA}_{\mathrm{MCA}}$ increases as the MCA diameter decreases, while $\mathrm{MFV}_{\mathrm{ICA}}$ remains unchanged, resulting in a higher LR. The pulsatility index can provide information regarding distal vascular resistance and intracranial compliance, although its clinical implications are less established (Fig. 2).

The correlation between TCD ultrasonography findings and angiographic vasospasm is most reliable for the MCA..$^{23,38,66}$ An MFV $<120 \mathrm{~cm} / \mathrm{sec}$ has a $94 \%$ negative predictive value, while an MFV $>200 \mathrm{~cm} / \mathrm{sec}$ has an $87 \%$ positive predictive value. ${ }^{71} \mathrm{MCA}$ vasospasm can be graded using the following criteria: mild, MFV $>120-150 \mathrm{~cm} / \mathrm{sec}$ or LR 3.0-4.5; moderate, MFV $>150-200 \mathrm{~cm} / \mathrm{sec}$ or LR 4.5-6.0; severe, MFV > $200 \mathrm{~cm} / \mathrm{sec}$ or LR $>6.0 .{ }^{45}$ Notably, TCD ultrasonography is less sensitive for ACA vasospasm, and patients with anterior communicating artery aneurysms are especially at high risk of false-negative

TABLE 1. Parameters used for positive identification of blood flow velocity in major intracranial vessels

\begin{tabular}{lccccc}
\hline \multicolumn{1}{c}{ Vessel } & Window & Depth $(\mathrm{mm})$ & Flow & Probe Angle & Normal Velocity (cm/sec) \\
\hline Terminal ICA & Temporal & $55-66$ & Toward & Anterosuperior & $39 \pm 9$ \\
\hline MCA & Temporal & $30-65$ & Toward & Anterosuperior & $55 \pm 12$ \\
\hline ACA & Temporal & $60-80$ & Away & Anterosuperior & $50 \pm 11$ \\
\hline PCA-P 1 & Temporal & $60-70$ & Toward & Posteroinferior & $39 \pm 10$ \\
\hline PCA-P & Temporal & $60-80$ & Away & Posteroinferior & $40 \pm 10$ \\
\hline Ophthalmic artery & Transorbital & $40-60$ & Toward & $15-20^{\circ}$ medial & $21 \pm 5$ \\
\hline ICA siphon & Transorbital & $60-80$ & Variable & Variable & $47 \pm 14$ \\
\hline BA & Transforaminal & $80-120$ & Away & Midline & $41 \pm 10$ \\
\hline Intracranial VA & Transforaminal & $60-90$ & Away & Paramedian & $38 \pm 10$ \\
\hline Extracranial VA & Inferior to mastoid & $45-55$ & Variable & Lateral-inferior & $38 \pm 10$ \\
\hline Extracranial ICA & Submandibular & $30-60$ & Away & Posterolateral & $37 \pm 9$ \\
\hline
\end{tabular}




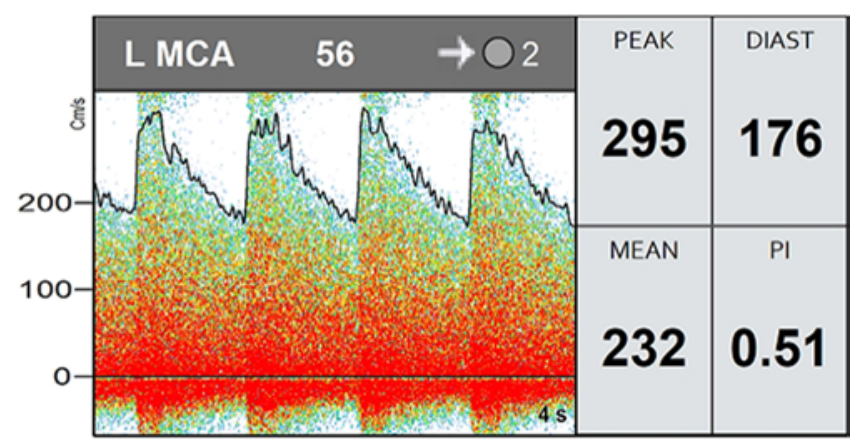

FIG. 1. Transcranial Doppler waveform showing elevated velocities in the left MCA, consistent with severe vasospasm. $\mathrm{PI}=$ pulsatility index.

findings. ${ }^{45}$ ACA vasospasm is more reliably predicted by a $50 \%$ or $50 \mathrm{~cm} / \mathrm{sec}$ increase in MFV over a 24-hour period. ${ }^{26}$ For the PCA, difficulty with insonation renders absolute velocity readings unreliable. ${ }^{73}$ Trends over time are likely more clinically relevant when assessing the ACA and PCA. As in the anterior circulation, velocities in the BA can be compared with those in the extracranial VA; $\mathrm{BA} /$ extracranial $\mathrm{VA}$ ratio $>3$ is associated with significant BA vasospasm. ${ }^{59}$ A recent meta-analysis of 17 studies including 2870 patients reported overall sensitivity of $90 \%$ and negative predictive value of $92 \%$ for the diagnosis of vasospasm with TCD ultrasonography. ${ }^{35}$

\section{Clinical Practice}

At our institution, TCD ultrasonography studies are obtained in SAH patients daily until 14 days postictus. TCD ultrasonography is used as a screening tool, and its findings are correlated with the clinical examination. Patients with mild and moderate vasospasm on TCD ultrasonography used to be empirically treated with hyperemia and permissive hypertension, although recent studies have called this practice into question; prophylactic hypertension is now typically reserved for patients in whom neurological examination is difficult due to coma or intubation. ${ }^{25}$ In patients with TCD ultrasonography evidence of vasospasm and new, lateralizing neurological deficit, digital subtraction angiography is often indicated for both diagnosis and treatment in the form of intraarterial vasodilators and/or balloon angioplasty. When the clinical examination and TCD ultrasonography findings are discordant or equivocal, CT angiography and CT perfusion can be used to determine candidacy for endovascular therapy.

\section{Monitoring After Neurosurgical Procedures Cerebrovascular Bypass}

Extracranial-to-intracranial bypass may be performed to augment hypoperfused vascular territories or to replace vessels that must be sacrificed in the course of an operation. ${ }^{47,57}$ Low-flow bypasses have a volume flow rate of < $65 \mathrm{~mL} / \mathrm{min}$ and typically involve smaller external carotid artery branches such as the superficial temporal artery directly anastomosed to intracranial vessels. ${ }^{47}$ In high-flow bypasses, a conduit such as a radial artery or saphenous vein graft is interposed between the extracranial and intracranial vessels. Flow rates for high-flow bypasses range

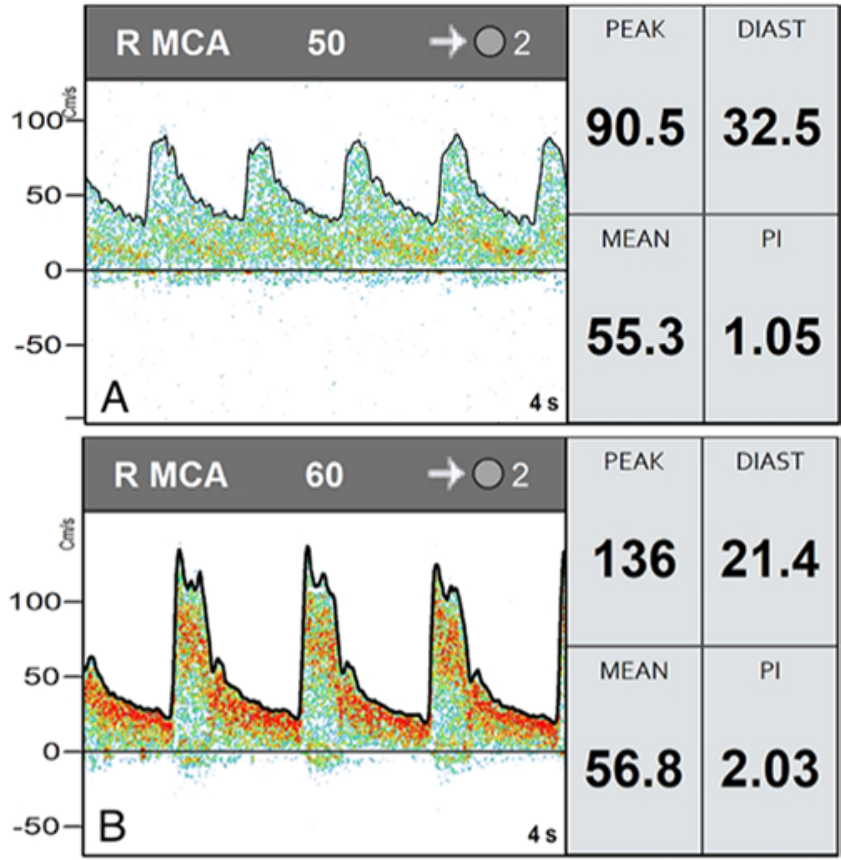

FIG. 2. The pulsatility index serves as a proxy for resistance to flow and ICP. It is calculated by dividing the difference between peak systolic and trough diastolic velocities by the mean velocity. A: Transcranial Doppler waveform with a normal pulsatility index. B: Transcranial Doppler waveform with an elevated pulsatility index.

between 65 and $200 \mathrm{~mL} / \mathrm{min} .{ }^{57}$ Postoperatively, brain perfusion is dependent on blood flow in the graft, and regular monitoring of flow rates can detect problems before the onset of ischemia. TCD ultrasonography is used to evaluate graft patency and quantify blood flow. ${ }^{47}$

In low-flow bypasses, the narrow lumen frequently renders accurate assessment of cross-sectional area and thus volume flow rates challenging; peak velocities are monitored instead. ${ }^{47}$ Duplex ultrasound is used to trace the graft from its origin to where it enters the skull, and peak velocities of the proximal, mid, and distal grafts are recorded. A focal increase in peak velocity or a slowed systolic upstroke suggests stenosis. For high-flow bypasses, the mean flow rate is around $130 \mathrm{~mL} / \mathrm{min}^{48}$ Flow rates $<65 \mathrm{~mL} / \mathrm{min}$ or $>200 \mathrm{~mL} / \mathrm{min}$ are associated with ischemia and hyperemia, respectively, requiring further evaluation. ${ }^{48}$

\section{Endovascular Neurosurgery}

TCD ultrasonography can be used to monitor for microembolic signals following endovascular aneurysm embolization and carotid stenting, as these signals are associated with the presence of postoperative ischemic lesions identified on diffusion-weighted imaging. ${ }^{711}$ Microemboli are high-intensity signals lasting $<0.1$ second with intensity 3-60 dB above background (Fig. 3) ${ }^{60}$ Emboli monitoring is often performed in the downstream artery after placement of an intracranial stent and after aneurysm coiling complicated by coil herniation into the parent vessel. Should a significant number of microembolic signals be detected, additional antithrombotic agents may be administered. 


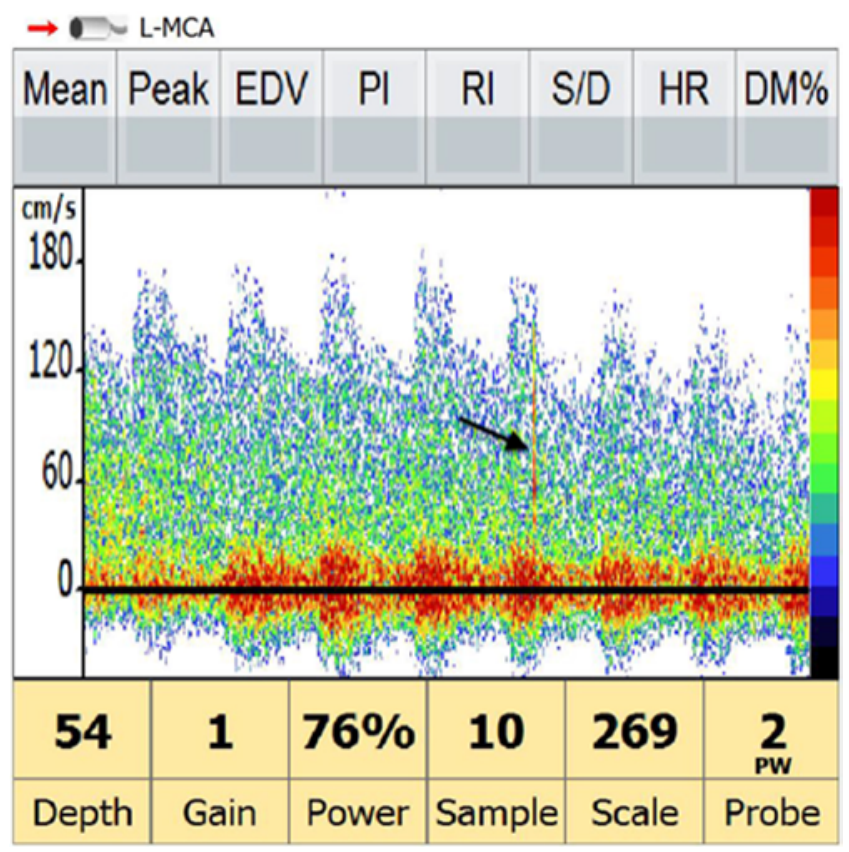

FIG. 3. Transcranial Doppler waveform demonstrating a high-intensity transient signal (arrow), consistent with microembolization. DM\% $=$ delta mean (monitoring mode); EDV = end-diastolic velocity; $\mathrm{HR}=$ heart rate; $\mathrm{RI}=$ resistance index; $\mathrm{S} / \mathrm{D}=$ systolic/diastolic flow ratio.

\section{Ischemic Stroke Diagnosis and Etiology}

While CT and MRI are the principal imaging modalities for the diagnosis of stroke, TCD ultrasonography can provide information about collateral flow, active embolization, subclavian steal, and even recanalization following thrombolytics. ${ }^{10,27,69}$ In the prehospital setting, paramedics may soon be able to use TCD ultrasonography as a screening tool for large vessel occlusions to assist with appropriate triage. ${ }^{67}$

TCD ultrasonography may assist with identification of stroke etiology. For example, carotid artery atherosclerosis, carotid artery dissection, atrial fibrillation, prosthetic heart valves, and fat emboli have all been identified as thromboembolic sources that can cause large vessel occlusions, and these lesions are commonly associated with detection of microemboli on TCD ultrasonography., ${ }^{9,32,53}$ In contrast, intracranial stenosis from vasospasm or atherosclerosis elevates CBF velocities, and lacunar strokes appear to alter the pulsatility index. ${ }^{15}$ Diagnosis of these latter etiologies frequently relies principally on $\mathrm{CT}$ and MRI findings, but microembolic signals detected by TCD ultrasonography complement these studies. ${ }^{14,32}$ For example, in stroke patients in whom both carotid atherosclerosis and atrial fibrillation have been diagnosed, the presence of microemboli in multiple arterial territories suggests a cardiogenic, rather than atherosclerotic, stroke source.

Cryptogenic strokes account for $17 \%$ of ischemic strokes and tend to occur in a thromboembolic pattern. ${ }^{28}$ As many as $38 \%$ of patients with cryptogenic strokes are found to have a right-to-left shunt, such as a patent foramen ovale (PFO), compared with just $18 \%$ in patients with a known etiology ${ }^{46}$ These shunts can be identified by administering contrast-enhanced media, such as agitated saline, and then monitoring for bubbles on echocardiography or on TCD ultrasonography. ${ }^{14}$ Traditionally, transesophageal echocardiography (TEE) has been the gold standard in the workup of cryptogenic stroke as most shunts are PFOs and TEE allows for direct visualization of intracardiac shunts. ${ }^{31}$ However, TCD emboli monitoring may become the gold standard for detecting right-to-left shunts, as these studies appear to have superior sensitivity and lower cost and can detect pulmonary shunts and small PFOs missed on TEE. ${ }^{68}$

\section{Prognosis and Management}

TCD microemboli monitoring provides prognostic value for monitoring symptomatic cerebrovascular disease. In one study, $45 \%$ of patients with symptomatic carotid artery stenosis had microembolic signals in the ipsilateral $\mathrm{MCA}$, and the presence of these signals corresponded to a significantly increased risk of subsequent ipsilateral stroke and transient ischemic attacks. ${ }^{44}$ Microembolic signals within the MCA also predict recurrent strokes caused by intracranial MCA-MCA embolization. ${ }^{24}$

Microemboli monitoring on TCD ultrasonography has also been used to monitor response to medications intended as secondary prevention for stroke. For example, dual antiplatelet therapy has been shown to reduce the frequency of microembolic signals by $61 \%$ compared with medical therapy with aspirin alone ${ }^{42}$ In this same study, 17 individuals $(16 \%)$ had suffered recurrent stroke or transient ischemia attack by the 1-week follow-up. Although this endpoint was not significantly different between groups, the frequency of microemboli signals per hour in these 17 patients was significantly greater than the frequency in the other 90 patients in the study. Overall, these findings suggest that monitoring of asymptomatic emboli with TCD ultrasonography can be used to assess the response to medical therapy and, further, to guide escalation of treatment as needed in patients who have suffered thromboembolic stroke.

Microembolic signals are less common in patients with asymptomatic carotid artery stenosis but indicate a higher risk of ischemic stroke. ${ }^{32}$ TCD microemboli monitoring may identify a small subset of high-risk patients with asymptomatic carotid stenosis who could benefit from a carotid endarterectomy. In asymptomatic patients with at least $70 \%$ stenosis, patients with microemboli had a 2 -year stroke risk of $3.6 \%$ compared with $0.7 \%$ in those without. ${ }^{43}$ Similarly, TCD ultrasonography has been used in conjunction with bubble studies on TEE to quantify severity of right-to-left shunting in an attempt to identify patients who may benefit from surgical closure of a PFO.68

In the setting of trauma, blunt cerebrovascular injury is seen in as many as $2.4 \%$ of patients admitted to the hospital with nonpenetrating injuries. ${ }^{8,61}$ These injuries confer a 5\%-10\% risk of stroke. ${ }^{19,56,62}$ The detection of microemboli distal to a high-grade carotid injury is associated with a 5-fold increase in the risk of stroke; ${ }^{8}$ TCD ultrasonography results may help to risk-stratify patients and guide the use of antithrombotic agents in this high-risk population.

Finally, arterial occlusions alter TCD waveforms in 
a reliable, quantifiable manner that can yield important prognostic information. For example, improved flow signals and reduction of flow pulsatility following systemic thrombolysis can indicate recanalization of the occluded artery. ${ }^{6}$ These waveform properties were used to develop the Thrombolysis in Brain Ischemia (TIBI) scale as a way to quantify recanalization, and, thus, a therapeutic response, following thrombolysis. ${ }^{16}$ In comparison with the gold standard of angiography, TCD ultrasonography has been shown to be nearly $90 \%$ accurate ${ }^{69}$ Patients with a TIBI grade of 5, or full recanalization, within 6 hours of symptom onset are substantially more likely to be functionally independent 3 months following a stroke. ${ }^{63}$ Additionally, preliminary research suggests that preservation of dynamic cerebral autoregulation, as identified by TCD ultrasonography, may predict better functional outcomes. ${ }^{40}$

\section{Primary Prevention in Sickle Cell Disease}

Large-vessel vasculopathy can result in severe strokes following obliteration of the ICAs or MCAs in approximately $1 \%$ of children with sickle cell disease. ${ }^{3}$ Prophylactic blood transfusions can mitigate the process, but the sequelae from chronic transfusions prevent this strategy from being employed indiscriminately. ${ }^{54}$ Peak velocities greater than $200 \mathrm{~cm} / \mathrm{sec}$ confer a 10\%-13\% annual elevated risk of stroke, ${ }^{3}$ and prophylactic transfusions triggered by serial TCD ultrasonography data reduce the annual risk of stroke by $90 \% .^{5}$ Since peak velocities decrease after transfusion, continued TCD ultrasonography monitoring with transfusions as indicated has proven to be a reliable means of protecting high-risk children. ${ }^{4}$ More recently, TCD ultrasonography has been used to safely guide the transition of children from chronic maintenance transfusions to hydroxyurea for primary stroke prevention. ${ }^{72}$

\section{Cerebral Autoregulation Testing}

Cerebral autoregulation refers to the brain's ability to maintain constant $\mathrm{CBF}$ in the face of varying cerebral perfusion pressure (CPP). In healthy individuals, the cerebral vascular resistance (CVR) varies with $\mathrm{CPP}$ to maintain constant CBF between mean arterial pressures (MAPs) of $60 \mathrm{~mm} \mathrm{Hg}$ and $150 \mathrm{~mm} \mathrm{Hg} .{ }^{37,64}$ Assessment of cerebral autoregulation can provide information valuable in the management of a range of neurosurgical conditions, including cerebrovascular stenosis and traumatic brain injury. TCD ultrasonography is an inexpensive and noninvasive means for assessing cerebral autoregulation at the bedside. While these methods do not directly measure parenchymal CBF and autoregulation, velocity changes in trunk vessels assessed by TCD ultrasonography have been shown to correlate well with perfusion as assessed by SPECT. ${ }^{20}$

\section{Cerebral Autoregulation in Cerebrovascular Ischemia}

In the setting of cerebrovascular atherosclerosis, resistance across a proximal stenosis decreases perfusion pressure to the downstream vascular territory. In order to compensate, the distal vasculature dilates, reducing overall CVR and preserving CBF. When the stenosis is critical, the distal vasculature may become maximally dilated, exhausting the ability of cerebral autoregulation to maintain $\mathrm{CBF}$ in the face of further decreased perfusion. This state has been termed "misery perfusion" and has important prognostic implications. Among patients with symptomatic cerebrovascular disease, misery perfusion is associated with a 6 -fold increase in the risk of subsequent stroke, highlighting the need for vigilance in the management of these patients. ${ }^{74}$

Autoregulatory reserve can be tested by measuring blood flow velocity distal to a stenotic or occlusive lesion before and after the administration of agents that challenge the normal autoregulatory response. When autoregulation is not exhausted, resistance arterioles at the pial surface dilate, leading to an increase in $\mathrm{CBF}$ in the trunk vessels that manifests on TCD ultrasonography as heightened blood flow velocity. When autoregulation is exhausted, the change in velocity is blunted or even nonexistent. In severe cases, a paradoxical decrease in velocity may be observed due to a steal phenomenon; areas with intact autoregulation may recruit additional CBF, siphoning flow away from the region with exhausted autoregulation. ${ }^{33}$

Inhaled carbon dioxide and acetazolamide are 2 agents that are commonly used to challenge autoregulatory reserve. Both act by decreasing the $\mathrm{pH}$ of extracellular fluid, which is a potent vasodilatory stimulus in the brain. Inhalation of $\mathrm{CO}_{2}$ acts by increasing the dissolved partial pressure of $\mathrm{CO}_{2}$ in blood, which in turn increases the concentration of carbonic acid, lowering the $\mathrm{pH}$. In our laboratory, vasomotor reserve (VMR) is defined as follows: $\mathrm{VMR}=\left(\mathrm{MFV}_{\text {hypercapnia }} / \mathrm{MFV}_{\text {baseline }}\right) \times 100-\left(\mathrm{MFV}_{\text {hypocapnia }} /\right.$ $\left.\mathrm{MFV}_{\text {baseline }}\right) \times 100 . .^{52}$ The test is performed by administering $5 \%$ inhaled $\mathrm{CO}_{2}$ and measuring MCA velocity after the end-tidal $\mathrm{CO}_{2}$ increases by $10 \mathrm{~mm} \mathrm{Hg}$ ( $\left.\mathrm{V}_{\text {hypercapnia }}\right)$. The patient then hyperventilates on room air until the end-tidal $\mathrm{CO}_{2}$ is reduced to $25 \mathrm{~mm} \mathrm{Hg}$, and the MCA velocity measurement is repeated $\left(\mathrm{V}_{\text {hypocapnia }}\right)$. In normal individuals, MCA velocity increases by $2 \%-4 \%$ per $\mathrm{mm} \mathrm{Hg}$ increase in $\mathrm{PaCO}_{2}{ }^{33,51} \mathrm{VMR}<15 \%$ is considered exhausted, $16 \%-$ $38 \%$ severely reduced, 39\%-69\% moderately reduced, and $\geq 70 \%$ normal.

Acetazolamide is a carbonic anhydrase inhibitor that acts to block the conversion of carbonic acid to $\mathrm{CO}_{2}$ and water, leading to a drop in $\mathrm{pH}$. The drug is a potent stimulus for cerebral vasodilation and in healthy individuals can increase flow by $30 \%-60 \%$. The estimated cerebrovascular reserve (eCVR) can be calculated using the following equation: $\mathrm{eCVR}=\left(\mathrm{MFV}_{\text {acetazolamide }}-\mathrm{MFV}_{\text {baseline }}\right) / \mathrm{MFV}_{\text {base- }}$ line $\times 100.33$

\section{Cerebral Autoregulation in Trauma}

Cerebral autoregulation impairment is present in between $49 \%$ and $87 \%$ of patients with severe TBI, ${ }^{51}$ placing these individuals at increased risk for ischemia with hypotension. In the absence of intact autoregulation, rapid increases in blood pressure may precipitate worsening cerebral edema, hemorrhage, and/or elevations in intracranial pressure (ICP). Disruptions in CBF are commonly seen in the tissue surrounding cerebral contusions, and hemispheric autoregulation tends to be more disrupted in the hemisphere containing mass lesions. ${ }^{41,55}$ Autoregulation impairment waxes and wanes over the course of a patient's ICU stay, with greater disruptions occurring early after in- 
jury. ${ }^{36}$ Impairments in autoregulation are associated with worse neurological outcome, particularly when unilateral or prolonged. ${ }^{29,50,51,70}$ Knowledge of autoregulation status facilitates tailored management of the TBI patient, as patients with intact autoregulation may see improvements in ICP control and brain tissue oxygenation with augmented CPP.

Two separate components of autoregulation can be assessed with TCD: the dynamic response, which considers the rate of autoregulatory compensation, and the static response, which is independent of time and measures compensation for sustained changes in CPP.

To assess dynamic autoregulation, a thigh blood pressure cuff is inflated $20 \mathrm{~mm} \mathrm{Hg}$ above systolic blood pressure for 3 minutes and then rapidly deflated, prompting a transient drop in blood pressure. The dynamic autoregulatory index (dARI) can be calculated by comparing preand postdeflation MCA velocities using the formula: dARI $=(\Delta \mathrm{eCVR} / \Delta \mathrm{T}) / \mathrm{MAP}$, where $\mathrm{eCVR}=\mathrm{MAP} / \mathrm{MFV}_{\mathrm{MCA}}$ and $\mathrm{T}=$ time. ${ }^{1}$ In trauma patients, assessment of autoregulation by this method may be precluded by hemodynamic instability or extracranial injuries.

Static autoregulation is assessed by pharmacological augmentation of MAP. Vasoactive agents are infused to achieve a $20-\mathrm{mm} \mathrm{Hg}$ increase in CPP. The static autoregulatory index (sARI) is defined as sARI = $\% \Delta \mathrm{eCVR} / \% \Delta \mathrm{CPP}^{65}$ When sARI is 0 , cerebral autoregulation is exhausted and CBF changes linearly with CPP. Values $\leq 0.39$ are considered impaired, and those $\geq 0.4$ are considered intact. Static autoregulation may also be assessed using Mx, defined as the correlation coefficient between CPP and MFV; autoregulation is impaired when $\mathrm{Mx}<0.3$ and intact when $\geq 0.3 .^{13}$

\section{Cerebral Circulatory Arrest}

In some cases, determination of brain death requires ancillary studies in support of clinical assessments. Identification of cerebral circulatory arrest with TCD ultrasonography is one commonly used modality. ${ }^{58}$ Once herniation has occurred and blood flow to the brain ceases, TCD ultrasonography may demonstrate reverberant flow, with equal antegrade systolic and retrograde diastolic velocities indicating the absence of net forward flow; narrow lowvelocity systolic spikes, consistent with flow cessation at the carotid siphon; and/or absence of intracranial flow in a patient where Doppler signals had previously been detected. ${ }^{18}$ Two examinations separated by 30 minutes should be performed to confirm the diagnosis. ${ }^{18}$

\section{Conclusions}

The indications for TCD ultrasonography in neurological surgery and neurocritical care have expanded significantly since this monitoring tool was first introduced. Today, TCD ultrasonography is used routinely in the management of SAH, occlusive cerebrovascular disease, traumatic brain injury, and other diseases. Familiarity with this noninvasive monitoring technique is important to the modern neurosurgeon.

\section{References}

1. Aaslid R, Lindegaard KF, Sorteberg W, Nornes H: Cerebral autoregulation dynamics in humans. Stroke 20:45-52, 1989

2. Aaslid R, Markwalder TM, Nornes H: Noninvasive transcranial Doppler ultrasound recording of flow velocity in basal cerebral arteries. J Neurosurg 57:769-774, 1982

3. Adams RJ: Big strokes in small persons. Arch Neurol 64:1567-1574, 2007

4. Adams RJ, Brambilla D: Discontinuing prophylactic transfusions used to prevent stroke in sickle cell disease. $\mathbf{N}$ Engl J Med 353:2769-2778, 2005

5. Adams RJ, McKie VC, Hsu L, Files B, Vichinsky E, Pegelow $C$, et al: Prevention of a first stroke by transfusions in children with sickle cell anemia and abnormal results on transcranial Doppler ultrasonography. N Engl J Med 339:5-11, 1998

6. Alexandrov AV, Demchuk AM, Wein TH, Grotta JC: Yield of transcranial Doppler in acute cerebral ischemia. Stroke 30:1604-1609, 1999

7. Almekhlafi MA, Demchuk AM, Mishra S, Bal S, Menon BK, Wiebe S, et al: Malignant emboli on transcranial Doppler during carotid stenting predict postprocedure diffusionweighted imaging lesions. Stroke 44:1317-1322, 2013

8. Bonow RH, Witt CE, Mosher BP, Mossa-Basha M, Vavilala MS, Rivara FP, et al: Transcranial Doppler microemboli monitoring for stroke risk stratification in blunt cerebrovascular injury. Crit Care Med 45:e1011-e1017, 2017

9. Brunser AM, Lavados PM, Hoppe A, Muñoz-Venturelli P, Sujima E, López J, et al: Transcranial Doppler as a predictor of ischemic events in carotid artery dissection. J Neuroimaging 27:232-236, 2017

10. Brunser AM, Mansilla E, Hoppe A, Olavarría V, Sujima E, Lavados PM: The role of TCD in the evaluation of acute stroke. J Neuroimaging 26:420-425, 2016

11. Cho JH, Kang DH, Kim YW, Park J, Kim YS: Microembolic signal monitoring and the prediction of thromboembolic events following coil embolization of unruptured intracranial aneurysms: diffusion-weighted imaging correlation. Neuroradiology 57:189-196, 2015

12. Connolly ES Jr, Rabinstein AA, Carhuapoma JR, Derdeyn CP, Dion J, Higashida RT, et al: Guidelines for the management of aneurysmal subarachnoid hemorrhage: a guideline for healthcare professionals from the American Heart Association/American Stroke Association. Stroke 43:1711-1737, 2012

13. Czosnyka M, Smielewski P, Kirkpatrick P, Menon DK, Pickard JD: Monitoring of cerebral autoregulation in head-injured patients. Stroke 27:1829-1834, 1996

14. D'Andrea A, Conte M, Cavallaro M, Scarafile R, Riegler L, Cocchia R, et al: Transcranial Doppler ultrasonography: from methodology to major clinical applications. World J Cardiol 8:383-400, 2016

15. de la Cruz-Cosme C, Dawid-Milner MS, Ojeda-Burgos G, Gallardo-Tur A, Segura T: Doppler resistivity and cerebral small vessel disease: hemodynamic structural correlation and usefulness for the etiological classification of acute ischemic stroke. J Stroke Cerebrovasc Dis 27:3425-3435, 2018

16. Demchuk AM, Burgin WS, Christou I, Felberg RA, Barber PA, Hill MD, et al: Thrombolysis in brain ischemia (TIBI) transcranial Doppler flow grades predict clinical severity, early recovery, and mortality in patients treated with intravenous tissue plasminogen activator. Stroke 32:89-93, 2001

17. Dorsch NW, King MT: A review of cerebral vasospasm in aneurysmal subarachnoid haemorrhage Part I: Incidence and effects. J Clin Neurosci 1:19-26, 1994

18. Ducrocq X, Hassler W, Moritake K, Newell DW, Reutern von GM, Shiogai T, et al: Consensus opinion on diagnosis of cerebral circulatory arrest using Doppler-sonography: Task Force Group on cerebral death of the Neurosonology Re- 
search Group of the World Federation of Neurology. J Neurol Sci 159:145-150, 1998

19. Eastman AL, Muraliraj V, Sperry JL, Minei JP: CTA-based screening reduces time to diagnosis and stroke rate in blunt cervical vascular injury. J Trauma 67:551-556, 2009

20. Engelhardt M, Pfadenhauer K, Zentner J, Grimmer S, Wachenfeld-Wahl C, Heidenreich P, et al: [Impaired cerebral autoregulation in asymptomatic patients with carotid artery stenosis: comparison of acetazolamide-SPECT and transcranial $\mathrm{CO}_{2}$-dopplersonography.] Zentralbl Chir 129:178-182, 2004 (German)

21. Fisher CM, Kistler JP, Davis JM: Relation of cerebral vasospasm to subarachnoid hemorrhage visualized by computerized tomographic scanning. Neurosurgery 6:1-9, 1980

22. Fisher CM, Roberson GH, Ojemann RG: Cerebral vasospasm with ruptured saccular aneurysm - the clinical manifestations. Neurosurgery 1:245-248, 1977

23. Fontanella M, Valfrè W, Benech F, Carlino C, Garbossa D, Ferrio M, et al: Vasospasm after SAH due to aneurysm rupture of the anterior circle of Willis: value of TCD monitoring. Neurol Res 30:256-261, 2008

24. Gao S, Wong KS, Hansberg T, Lam WWM, Droste DW, Ringelstein EB: Microembolic signal predicts recurrent cerebral ischemic events in acute stroke patients with middle cerebral artery stenosis. Stroke 35:2832-2836, 2004

25. Gathier CS, van den Bergh WM, van der Jagt M, Verweij BH, Dankbaar JW, Müller MC, et al: Induced hypertension for delayed cerebral ischemia after aneurysmal subarachnoid hemorrhage: a randomized clinical trial. Stroke 49:76-83, 2018

26. Grosset DG, Straiton J, McDonald I, Cockburn M, Bullock R: Use of transcranial Doppler sonography to predict development of a delayed ischemic deficit after subarachnoid hemorrhage. J Neurosurg 78:183-187, 1993

27. Guan J, Zhou Q, Ouyang H, Zhang S, Lu Z: The diagnostic accuracy of TCD for intracranial arterial stenosis/occlusion in patients with acute ischemic stroke: the importance of time interval between detection of TCD and CTA. Neurol Res 35:930-936, 2013

28. Hart RG, Catanese L, Perera KS, Ntaios G, Connolly SJ: Embolic stroke of undetermined source: a systematic review and clinical update. Stroke 48:867-872, 2017

29. Hockel K, Diedler J, Neunhoeffer F, Heimberg E, Nagel C, Schuhmann MU: Time spent with impaired autoregulation is linked with outcome in severe infant/paediatric traumatic brain injury. Acta Neurochir (Wien) 159:2053-2061, 2017

30. Inagawa T, Yahara K, Ohbayashi N: Risk factors associated with cerebral vasospasm following aneurysmal subarachnoid hemorrhage. Neurol Med Chir (Tokyo) 54:465-473, 2014

31. Katsanos AH, Psaltopoulou T, Sergentanis TN, Frogoudaki A, Vrettou AR, Ikonomidis I, et al: Transcranial Doppler versus transthoracic echocardiography for the detection of patent foramen ovale in patients with cryptogenic cerebral ischemia: a systematic review and diagnostic test accuracy meta-analysis. Ann Neurol 79:625-635, 2016

32. King A, Markus HS: Doppler embolic signals in cerebrovascular disease and prediction of stroke risk: a systematic review and meta-analysis. Stroke 40:3711-3717, 2009

33. Krejza J, Arkuszewski M: Neurosonology: transcranial Doppler and transcranial color-coded duplex sonography, in Le Roux PD, Levine JM, Kofke WA (eds): Monitoring in Neurocritical Care. Philadelphia: Elsevier, 2013, pp 300313

34. Krejza J, Swiat M, Pawlak MA, Oszkinis G, Weigele J, Hurst RW, et al: Suitability of temporal bone acoustic window: conventional TCD versus transcranial color-coded duplex sonography. J Neuroimaging 17:311-314, 2007

35. Kumar G, Shahripour RB, Harrigan MR: Vasospasm on transcranial Doppler is predictive of delayed cerebral ische- mia in aneurysmal subarachnoid hemorrhage: a systematic review and meta-analysis. J Neurosurg 124:1257-1264, 2016

36. Lang EW, Yip K, Griffith J, Lagopoulos J, Mudaliar Y, Dorsch NW: Hemispheric asymmetry and temporal profiles of cerebral pressure autoregulation in head injury. J Clin Neurosci 10:670-673, 2003

37. Lassen NA: Cerebral blood flow and oxygen consumption in man. Physiol Rev 39:183-238, 1959

38. Lennihan L, Petty GW, Fink ME, Solomon RA, Mohr JP: Transcranial Doppler detection of anterior cerebral artery vasospasm. J Neurol Neurosurg Psychiatry 56:906-909, 1993

39. Lindegaard KF, Nornes H, Bakke SJ, Sorteberg W, Nakstad P: Cerebral vasospasm after subarachnoid haemorrhage investigated by means of transcranial Doppler ultrasound. Acta Neurochir Suppl (Wien) 42:81-84, 1988

40. Ma H, Guo ZN, Jin H, Yan X, Liu J, Lv S, et al: Preliminary study of dynamic cerebral autoregulation in acute ischemic stroke: association with clinical factors. Front Neurol 9:1006, 2018

41. Marion DW, Darby J, Yonas H: Acute regional cerebral blood flow changes caused by severe head injuries. J Neurosurg 74:407-414, 1991

42. Markus HS, Droste DW, Kaps M, Larrue V, Lees KR, Siebler $\mathrm{M}$, et al: Dual antiplatelet therapy with clopidogrel and aspirin in symptomatic carotid stenosis evaluated using Doppler embolic signal detection: the Clopidogrel and Aspirin for Reduction of Emboli in Symptomatic Carotid Stenosis (CARESS) trial. Circulation 111:2233-2240, 2005

43. Markus HS, King A, Shipley M, Topakian R, Cullinane M, Reihill S, et al: Asymptomatic embolisation for prediction of stroke in the Asymptomatic Carotid Emboli Study (ACES): a prospective observational study. Lancet Neurol 9:663-671, 2010

44. Markus HS, MacKinnon A: Asymptomatic embolization detected by Doppler ultrasound predicts stroke risk in symptomatic carotid artery stenosis. Stroke 36:971-975, 2005

45. Marshall SA, Nyquist P, Ziai WC: The role of transcranial Doppler ultrasonography in the diagnosis and management of vasospasm after aneurysmal subarachnoid hemorrhage. Neurosurg Clin N Am 21:291-303, 2010

46. Mazzucco S, Li L, Binney L, Rothwell PM: Prevalence of patent foramen ovale in cryptogenic transient ischaemic attack and non-disabling stroke at older ages: a populationbased study, systematic review, and meta-analysis. Lancet Neurol 17:609-617, 2018

47. Morton RP, Abecassis IJ, Moore AE, Kelly CM, Levitt MR, Kim LJ, et al: The use of ultrasound for postoperative monitoring of cerebral bypass grafts: a technical report. J Clin Neurosci 40:169-174, 2017

48. Morton RP, Moore AE, Barber J, Tariq F, Hare K, Ghodke $\mathrm{B}$, et al: Monitoring flow in extracranial-intracranial bypass grafts using duplex ultrasonography: a single-center experience in 80 grafts over 8 years. Neurosurgery 74:62-70, 2014

49. Nelson TR, Pretorius DH: The Doppler signal: where does it come from and what does it mean? AJR Am J Roentgenol 151:439-447, 1988

50. Preiksaitis A, Krakauskaite S, Petkus V, Rocka S, Chomskis $\mathrm{R}$, Dagi TF, et al: Association of severe traumatic brain injury patient outcomes with duration of cerebrovascular autoregulation impairment events. Neurosurgery 79:75-82, 2016

51. Rangel-Castilla L, Gasco J, Nauta HJW, Okonkwo DO, Robertson CS: Cerebral pressure autoregulation in traumatic brain injury. Neurosurg Focus 25(4):E7, 2008

52. Ringelstein EB, Sievers C, Ecker S, Schneider PA, Otis SM: Noninvasive assessment of CO2-induced cerebral vasomotor response in normal individuals and patients with internal carotid artery occlusions. Stroke 19:963-969, 1988

53. Ritter MA, Dittrich R, Thoenissen N, Ringelstein EB, Nabavi DG: Prevalence and prognostic impact of microembolic sig- 
nals in arterial sources of embolism. A systematic review of the literature. J Neurol 255:953-961, 2008

54. Russell MO, Goldberg HI, Hodson A, Kim HC, Halus J, Reivich M, et al: Effect of transfusion therapy on arteriographic abnormalities and on recurrence of stroke in sickle cell disease. Blood 63:162-169, 1984

55. Schmidt EA, Czosnyka M, Steiner LA, Balestreri M, Smielewski P, Piechnik SK, et al: Asymmetry of pressure autoregulation after traumatic brain injury. J Neurosurg 99:991-998, 2003

56. Scott WW, Sharp S, Figueroa SA, Eastman AL, Hatchette $\mathrm{CV}$, Madden CJ, et al: Clinical and radiological outcomes following traumatic Grade 3 and 4 vertebral artery injuries: a 10-year retrospective analysis from a Level I trauma center. The Parkland Carotid and Vertebral Artery Injury Survey. J Neurosurg 122:1202-1207, 2015

57. Sekhar LN, Bucur SD, Bank WO, Wright DC: Venous and arterial bypass grafts for difficult tumors, aneurysms, and occlusive vascular lesions: evolution of surgical treatment and improved graft results. Neurosurgery 44:1207-1224, 1999

58. Sharma D, Souter MJ, Moore AE, Lam AM: Clinical experience with transcranial Doppler ultrasonography as a confirmatory test for brain death: a retrospective analysis. Neurocrit Care 14:370-376, 2011

59. Soustiel JF, Shik V, Shreiber R, Tavor Y, Goldsher D: Basilar vasospasm diagnosis: investigation of a modified "Lindegaard index" based on imaging studies and blood velocity measurements of the basilar artery. Stroke 33:72-77, 2002

60. Spencer MP: Detection of cerebral arterial emboli, in Newell DW, Aaslid R (eds): Transcranial Doppler. New York: Raven Press, 1992, pp 215-230

61. Stein DM, Boswell S, Sliker CW, Lui FY, Scalea TM: Blunt cerebrovascular injuries: does treatment always matter? J Trauma 66:132-144, 2009

62. Stein SC, Levine JM, Nagpal S, LeRoux PD: Vasospasm as the sole cause of cerebral ischemia: how strong is the evidence? Neurosurg Focus 21(3):E2, 2006

63. Stolz E, Cioli F, Allendoerfer J, Gerriets T, Del Sette M, Kaps M: Can early neurosonology predict outcome in acute stroke?: a metaanalysis of prognostic clinical effect sizes related to the vascular status. Stroke 39:3255-3261, 2008

64. Strandgaard S, Olesen J, Skinhoj E, Lassen NA: Autoregulation of brain circulation in severe arterial hypertension. BMJ 1:507-510, 1973

65. Strebel S, Lam AM, Matta B, Mayberg TS, Aaslid R, Newell DW: Dynamic and static cerebral autoregulation during isoflurane, desflurane, and propofol anesthesia. Anesthesiology 83:66-76, 1995

66. Suarez JI, Qureshi AI, Yahia AB, Parekh PD, Tamargo RJ, Williams MA, et al: Symptomatic vasospasm diagnosis after subarachnoid hemorrhage: evaluation of transcranial Doppler ultrasound and cerebral angiography as related to compromised vascular distribution. Crit Care Med 30:1348-1355, 2002
67. Thorpe SG, Thibeault CM, Canac N, Wilk SJ, Devlin T, Hamilton RB: Decision criteria for large vessel occlusion using transcranial Doppler waveform morphology. Front Neurol 9:847, 2018

68. Tobe J, Bogiatzi C, Munoz C, Tamayo A, Spence JD: Transcranial Doppler is complementary to echocardiography for detection and risk stratification of patent foramen ovale. Can J Cardiol 32:986.e9-986.e16, 2016

69. Tsivgoulis G, Ribo M, Rubiera M, Vasdekis SN, Barlinn K, Athanasiadis D, et al: Real-time validation of transcranial Doppler criteria in assessing recanalization during intra-arterial procedures for acute ischemic stroke: an international, multicenter study. Stroke 44:394-400, 2013

70. Vavilala MS, Lee LA, Boddu K, Visco E, Newell DW, Zimmerman JJ, et al: Cerebral autoregulation in pediatric traumatic brain injury. Pediatr Crit Care Med 5:257-263, 2004

71. Vora YY, Suarez-Almazor M, Steinke DE, Martin ML, Findlay JM: Role of transcranial Doppler monitoring in the diagnosis of cerebral vasospasm after subarachnoid hemorrhage. Neurosurgery 44:1237-1248, 1999

72. Ware RE, Davis BR, Schultz WH, Brown RC, Aygun B, Sarnaik $\mathrm{S}$, et al: Hydroxycarbamide versus chronic transfusion for maintenance of transcranial doppler flow velocities in children with sickle cell anaemia-TCD With Transfusions Changing to Hydroxyurea (TWiTCH): a multicentre, openlabel, phase 3, non-inferiority trial. Lancet 387:661-670, 2016

73. Wozniak MA, Sloan MA, Rothman MI, Burch CM, Rigamonti D, Permutt T, et al: Detection of vasospasm by transcranial Doppler sonography. The challenges of the anterior and posterior cerebral arteries. J Neuroimaging 6:87-93, 1996

74. Yamauchi H, Higashi T, Kagawa S, Nishii R, Kudo T, Sugimoto K, et al: Is misery perfusion still a predictor of stroke in symptomatic major cerebral artery disease? Brain 135:25152526, 2012

\section{Disclosures}

Dr. Levitt: direct stock ownership in Cerebrotech, eLoupes Inc., and Corindus, and unrestricted educational grants from Stryker, Medtronic, and Philips Volcano.

\section{Author Contributions}

Conception and design: Levitt, Bonow. Drafting the article: Bonow, Young, Bass. Critically revising the article: Levitt, Bonow, Moore. Reviewed submitted version of manuscript: all authors. Approved the final version of the manuscript on behalf of all authors: Levitt.

\section{Correspondence}

Michael R. Levitt: c/o Neurosurgery Publications, University of Washington, Seattle, WA.respub@uw.edu. 